REFERENCE NUMBER B 1.1

Kenneth W. Shepard

Phone: 708-252-4899

FAX: 708-252-9647

MAIIING ADDRESS:

Physics Division, Bldg. 203

Argonne National Laboratory

9700 South Cass Avenue

Argonne, II. 60439 USA

\title{
Superconducting heavy-ion accelerating structures
}

Kenneth W. Shepard

Physics Division, Argonne National Laboratory, 9700 South Cass Avenue, Argonne, II 60439, USA

This paper briefly reviews the technical history of superconducting ion-accelerating structures . Various superconducting cavities currently used and being developed for use in ion linacs are discussed. The principal parameters and operational characteristics of superconducting structures in active use at various heavy-ion facilities are described.

\section{Introduction}

For nearly two decades, superconducting if structures have been in use in heavy-ion booster linacs, increasing the energy of beams from tandem electrostatic accelerators [1,2]. This application has grown slowly but steadily, and, at the present time, some ten different superconducting linacs totaling nearly 200 MV of accelerating potential have been built or are under construction.. The booster linacs are used for nuclear structure experiments at and near the coulomb barrier, and also for atomic physics and other applications. A primary consideration in the development of booster linacs has been to preserve the high beam quality, energy variability, and flexibility of operation characteristic of electrostatic machines. Another important consideration has been to efficiently use the low-current, dc beams coming from tandem accelerators. A booster linac is configured as an independently-phased array of short resonant cavity accelerating structures, each structure being short to achieve a relatively broad velocity acceptance. By 


\section{DISCLAIMER}

Portions of this document may be illegible in electronic image products. Images are produced from the best available original document. 
appropriately adjusting the If phase of each cavity in the array, the velocity profile of the linac can be modified to permit the acceleration of ions of various charge-to-mass ratios. Because of the requirement of short accelerating structures, low operating frequencies are used to make the structures as long as possible, so that the accelerating voltage per structure is maximized. A low operating frequency also enhances beam quality and transmission, both by providing a large transverse aperture and also by maximizing the timespread available for a beam bunch. These features ensure a highly linear, emittance-preserving beam-cavity interaction.

Beam currents from electrostatic machines are usually small, typically a few particle-nanoamperes, So that the If power requirements are determined almost entirely by if losses in the accelerating cavities. Since the shunt impedance of normally-conducting low-velocity accelerating structures is generally low, the use of superconducting if structures can greatly reduce if power requirements, particularly when continuous (cw) operation is required. For booster linacs, $c w$ operation is needed both to efficiently utilize the dc beam from tandem electrostatic machines and also to avoid transients which degrade beam quality. For these reasons, and other reasons discussed below, heavy-ion booster linacs were, at the outset of development, seen as a highly favorable area for the application of superconducting if technology.

\section{Early work: technical basics}

The use of superconducting cavities in a particle accelerator was proposed soon after a basic understanding of the if properties of superconductors was achieved [3,4]. In 1960, Banford and Stafford proposed the use of superconducting lead if cavities to form a proton linac [5]. This early paper pointed out that the ratio of the measured superconducting surface resistance of lead at $4.2 \mathrm{~K}$ to copper at room temperature was sufficiently high, that even including a factor of 1000 to allow for the efficiency of the then-available refrigeration systems, the total power required for a proton linac could be greatly reduced by the use of superconducting accelerating structures.

A modest early experiment aimed at accelerator applications was the fabrication and testing of a niobium $270 \mathrm{MHz}$ quarter-wave coaxial-line resonant cavity at CERN in 1962 [6]. This cavity performed 
poorly, exhibiting high rf losses, and the effort was not pursued. It provided, however, the first indication of the difficulties that would be encountered in producing the defect-free superconducting surfaces required for good cavity performance.

The first demonstration of useful performance was made at Stanford in 1965 in tests of superconducting lead cylindrical $x$-band cavities, initially in single-cell and subsequently in multi-cell configuration [7]. This work was the experimental foundation for the superconducting accelerator project at Stanford's high-energy physics laboratory (HEPL). This project, an electron linac based on multi-cell 1.3 GHz niobium cavities, was the first application of if superconductivity to particle acceleration [8]. The HEPL linac did not fully attain the accelerating gradients which had been optimistically anticipated early in the project, primarily because of high-field multipacting. Even so, this pioneering project successfully addressed virtually all of the major problems of the technology, including resonator design, fabrication, and operation, cryostat design and helium refrigeration below $2 \mathrm{~K}$ : the linac which was built is still in occasional use.

Several years after the start of the Stanford project, an effort to build a high-current superconducting proton linac began at the laboratory for nuclear research at Karlsruhe [9]. This project focused on the development of various slow-wave structures suitable for accelerating protons and heavier ions. Both multi-section helically-loaded cavities and Alverez-type drift tube structures were fabricated from niobium and tested $[10,11]$. Although adequate accelerating gradients were achieved, the poor mechanical stability of the helically-loaded structures resulted in if eigenfrequency fluctuations that made control of the If phase extremely difficult. After a substantial effort, beam was accelerated through two $6 \lambda / 2$ cavities, but the difficulty of controlling if phase severely limited accelerating gradients [12, 13].

In the period 1969-1971, during the early enthusiasm for the two major projects described above, four different laboratories began to develop accelerating structures to be used in small linacs to boost the energy of ion beams from tandem Van de Graaf accelerators. Groups at Argonne National Laboratory, the California Institute of Technology, and Karlsruhe began with developing helically-loaded slow-wave structures [14-16]. At Stanford University a cylindrically symmetric, re-entrant cavity geometry was pursued [17]. In order to discuss these four projects in cetail, it is useful first to review some of the basic 
technical features of superconducting if technology, particularly as applied to the acceleration of heavy ions $[1,2]$.

A fundamental difference between dc and if applications of superconductors results from the fact that for a dc application, use of a superconductor in the mixed state is permissible, since any steady-state dc current will be entirely supercurrent, flowing around, not through, any normal regions. At the surface of an If cavity, however, the distribution of current is determined not by the surface resistance of the cavity wall, but almost entirely by the reactive impedance associated with the time-varying electromagnetic fields. Consequently, rf currents will not in general bypass a normal region (defect) in a superconducting cavity surface, but rather flow through it, with consequent joule heating proportional to area of the defect and the normal-state surface resistance. If the temperature rise associated with the joule heating exceeds the few degrees needed to reach the superconducting transition temperature, then thermal instability results and a normal region will grow in size, the heating driven by the energy released by collapse of the rf field within the resonant cavity. Much of the development of superconducting if technology has concerned reducing the number and size of defective regions, and increasing the thermal stability of the rf cavity wall.

The difficulties encountered in phase-stabilizing helically-loaded resonators which were previously mentioned are a manifestation of a general problem in the operation of superconducting low-velocity accelerating structures [13]. Matching an if cavity to particle velocities substantially less than c requires a cavity geometry loaded either with a reduced capacitive gap or an extended inductive structure, either of which reduce mechanical stability. The lower the particle velocity to be matched, the greater the degree of loading and the less the mechanical stability. Ambient acoustic noise (microphonics) excites mechanical vibrational modes of the If cavity, causing the if eigenfrequency to vary. The range of variation depends on the mechanical properties of the superconducting cavity and ambient acoustic conditions, but is generally larger than the intrinsic if bandwidth, typically $0.1 \mathrm{~Hz}$ or less. For use in an accelerator, the cavity if phase must be synchronized with an if clock. In the presence of mechanically-induced if eigenfrequency jitter, this requires either driving the cavity at a frequency different than the resonant frequency, or tuning the If cavity sufficiently rapidly to follow the mechanical vibrations. Either method requires a control system to provide or switch a (reactive) If power given by 


$$
\mathrm{P}_{\text {tose }}=\mathrm{U} \xi \delta \omega
$$

where $U$ is the if energy content of the cavity and $\delta \omega$ is the if tuning range in angular frequency. If vibrational effects cause $P_{\text {tone }}$ to become larger than a few kilowatts, the primary advantage of a superconducting structure, reduced if power, is lessened, particularly for applications involving low beam currents.

Poor mechanical stability can cause additional problems. At high fields, radiation pressure distorts the cavity, and causes a static eigenfrequency shift, which is quadratic in the If field level. In the case of helically-loaded structures this shift can amount to several percent in absolute frequency. Such a change in eigenfrequency with If field amplitude constitutes a strong coupling of the phase and amplitude and greatly complicates the task of phase and amplitude control. Such phase-amplitude coupling can give rise to rfdriven mechanical oscillations, a manifestation of the so-called ponderomotive instability.

There are several factors which make a booster linac application particularly favorable for the use of if superconductivity :

1. Because of generally low beam currents in this application, the if power reduction achieved by using superconducting cavities is particularly large. Low-velocity structures generally exhibit low shunt impedance, so that great advantage is gained by using SC structures. Also, to achieve the broad velocity acceptance required in a booster linac, short if cavities must be used, in which end-effects reduce the shunt impedance even further.

2. A booster linac is necessarily formed as an array of independently-phased modules. These modules can be tuned not only to accommodate different beams but also to accommodate variations in the performance of individual resonant cavities. This feature greatly enhances the reliability of the array as a whole and, historically, reduced the perceived risk in using a new technology for a linac.

3. The superconducting surface resistance decreases rapidly with decreasing frequency. Since low frequencies are required for booster linacs, the superconducting surface resistance is very low in this application. This factor both permits operation of superconducting cavities at $4.5 \mathrm{~K}$ and above, and also enables the use of superconducting materials other than niobium, such as lead electroplated onto copper. Since the normalstate surface resistance is also reduced at low frequencies, thermal stability is enhanced [2]. 


\section{Heavy-ion booster linac projects}

The heavy-ion booster development at Karlsruhe was an adjunct to the superconducting proton linac project. $\lambda / 2$ helically loaded structures were developed for possible use in a booster linac for the MP tandem at Heidelberg. Although high if fields were achieved, mechanical stability of the cavities was poor. A fast-tuning system originally developed for the longer and more difficult to control $6 \lambda / 2$ helix structures was used with the shorter $\lambda / 2$ structures. Even so phase control still proved difficult, and the accelerating gradients achieved were not large. As a result, the Heidelberg group decided to use normal-conducting rather than superconducting cavities for their booster linac [18]. Several years later, further development of the helical geometry resulted in helical structures which exhibited somewhat greater mechanical stability. These were used in the heavy-ion booster linac built at Saclay, which operated from 1988 to 1994 [19].

Development at the California Institute of Technology began with $\lambda / 2$ helically-loaded cavities made of lead plated onto copper [15]. The relative simplicity of lead-on-copper technology facilitated the development of new structures, and several alternatives to the helix were created. Improved mechanical and electrodynamic properties were demonstrated in first the spiral-loaded [20] and subsequently the split-ring [21] cavity geometry (see Figure 2). The split-ring cavities developed at Cal Tech were used for the superconducting booster linac at the State University of New York at Stony Brook, which began operation in $1983[22,23]$.

Initial work at Argonne National Laboratory began with niobium helically-loaded structures similar to those developed at Karlsruhe[24]. Because of the difficulty of phase-stabilizing the helix, the Argonne group in 1975 began developing a niobium version of the split-ring geometry [25]. Phase stable operation of a split-ring at gradients above $3 \mathrm{MV} / \mathrm{m}$ was achieved in 1977, and this type of cavity was the basis for the booster linac at Argonne, the first superconducting heavy-ion linac, which began operating in 1978 [26].

At Stanford, heavy-ion accelerating structures were developed in collaboration with the superconducting electron linac group. Single-cell, cylindrically symmetric, highly-reentrant $425 \mathrm{MHz}$ 
niobium cavities were the chosen geometry and were developed to the point of testing a pair of cavities with beam [27]. An advantage of this class of structure is the very broad velocity-acceptance characteristic. A disadvantage is the large number of cavities required for a linac, because of the short active length of the structure.

All four of the initial development projects were completed in the sense of developing viable superconducting ion accelerating structures, which are shown in Figure 1. All the structures succeeded in accelerating heavy ions in demonstration tests. The two split-ring structures, however, were the only of these structures actually used to construct booster linacs

Table I details the various superconducting structures used to date in superconducting ion linacs, including two linacs presently under construction. . The different institutions shown in Table I appear in the sequence in which the associated heavy-ion linacs became operational Those structures for which the date of first operation is preceded by an asterisk are no longer operational. The entries in Table I for the number of resonators on-line and for the average accelerating gradient $\mathrm{E}_{\mathbf{a}}$ are the most recently available values. The values of $E_{p}, B_{p}$, and $R F$ Energy given for each structure are referred to an accelerating field level of $1 \mathrm{MV} / \mathrm{m}$. The accelerating field level is given in $\mathrm{MV} / \mathrm{m}$ and is defined as the energy gain per unit charge for a synchronous particle, averaged over the interior length of the cavity, also shown in Table 1. The voltage gain per cavity (for a synchronous particle) can thus be obtained by multiplying Ea by the length. The accelerating fields shown are the average values actually obtained in recently scheduled on-line operation. These values provide a 'snap-shot' of performance at the time of writing., but it should be understood that the gradients shown are not necessarily the limits of the facilities, since in many cases they are limited by non-essential problems which will be corrected by routine maintenance and/or planned upgrades.

The success of the first booster linacs motivated the use of the split ring structures in several additional facilities. The Argonne-developed niobium split ring is used in two additional booster linacs, which began operation at Florida State University in 1987 [38] and at Kansas State University in 1990 [39], as well as a booster linac currently under construction at the University of Sao Paulo [40]. The Cal 
Tech - Stony Brook lead on copper split ring is also employed in a booster linac which was initially located at Oxford University and is currently operated at the Australian National University in Canberra [41].

Nuclear physicists at the University of Washington, interested in constructing a linac with good performance for protons as well as heavy ions, joined an ongoing collaboration of workers at the Weirmann Institute and SUNY Stony Brook to develop the coaxial quarter-wave line resonator (QWR), an example of which is shown in Figure 3. The QWR structure is characterized by excellent mechanical stability and a very broad velocity acceptance, making it particularly well suited for a booster required to accelerate ions of a wide range of mass $[23,34]$.

At Argonne, the mechanical stability of the QWR geometry was exploited in developing a lowfrequency, four-gap interdigital structure, which proved sufficiently stable mechanically to extend the velocity range of superconducting structures down to $\beta=.008$. In a recent project, the so-called uranium upgrade, eighteen interdigital resonators were combined with an (ECR) positive ion source, capable of producing very high positive charge states. The resulting linac, termed the positive ion injector, has replaced the tandem electrostatic accelerator as the injector for the ATLAS linac [30,42]. The resulting machine has transcended the category of booster linac and is a stand-alone superconducting machine capable of accelerating ions as heavy as uranium to energies of $5 \mathrm{MeV}$ per nucleon and above.

Several recent booster linac projects have further developed various versions of the $Q W R$ resonator. At the Japan Atomic Energy Research Institute (JAERD), a booster linac consisting of 44 niobium QWR structures has achieved an average gradient exceeding $5 \mathrm{MV} / \mathrm{m}$ in regular operation $[35,43]$. In a collaborative effort, the Center for Nuclear Research at New Delhi is developing a $97 \mathrm{MHz}$, all-niobium QWR structure at Argonne National Laboratory for use in a booster linac at New Delhi $[37,44]$.

Several different structures are being developed for the booster linac at INFN Legnaro, an initial phase

of which is operational [45]. In a collaboration with the Weizmann Institute, a $160 \mathrm{MHz}$ QWR was developed, using lead electroplated onto copper: 48 of these structures form a portion of the booster [36]. A lower-velocity, $80 \mathrm{MHz}$ QWR built of niobium has also been developed, and the first of these operated online with good results [46]. The Legnaro group has successfully developed the use of niobium sputtered 
onto copper for ion accelerating structures [47]. Although this technique has been used for forming highvelocity, electron accelerating structures, the more complex geometry of low-velocity structures complicates this application. The recent operation at Legnaro of a cryostat module containing four such sputtered QWR structures has yielded promising results, although the accelerating gradients obtained in this preliminary test should not be taken as indicative of the full potential of the sputtered cavities [46].

\section{Other superconducting ion accelerating structures}

Superconducting structures intended for the acceleration of intense beams of light ions have been designed and have exhibited very high accelerating gradients in tests without beam. Three such structures have been examined, a $400 \mathrm{MHz}$ QWR structure, which achieved Ea = $13 \mathrm{MV} / \mathrm{m}$, and a $355 \mathrm{MHz}$ half-wave resonant line structure which operated at $18 \mathrm{MV} / \mathrm{m}$ [48].

Several groups have or are attempting various forms of superconducting RF quadrupole structure. Very high electric quadrupole fields were obtained in a test of a niobium quadrupole structure at Argonne, and while the structure tested was not suitable for accelerating beam, the results indicate considerable promise for this application [49]. At SUNY Stony Brook, a low-frequency, short RFQ made of lead electroplated onto copper has been tested with some success, however phase-stable operation at useful accelerating gradients remains to be demonstrated for this structure [50]. At Argonne, a $194 \mathrm{MHz}$ niobium RFQ is under construction, but has not yet been tested [51].

\section{Acknowledgements}

Many individuals at various institutions have been forthcoming and candid in providing information about current on-line operational characteristics of the existing booster linacs. It should be understood that the numbers provided represent a 'snap-shot' view of performance, which in many instances is determined by being a preliminary result for systems under development, or a result limited by known, in some cases trivial, outstanding maintenance tasks. 
This work was supported by the U. S. Department of Energy, Nuclear Physics Division, under contract 2-31-109-ENG-38.

\section{References}

[1] L. M. Bollinger, Annu. Rev. Nucl. Part. Sci. 36 (1986) 475.

[2] H. Padamsee, K. W. Shepard, and R. Sundelin, Annu. Rev. Nucl. Part. Sci. 43 (1993) 635.

[3] J . Bardeen, et al., Phys. Rev. 108 (1957) 1175.

[4] D. C. Mattis and J. Bardeen, Phys Rev. 111 (1958) 412.

[5] A. P. Banford and G. H. Stafford, Plasma Physics (Journal of Nuclear Energy C) VoL. 3 (1961) 287.

[6] L. Rinderer, et al., Physics Letters 2 (1962) 119.

[7] J. M. Pierce, et al., Proc. of the 9th Int. Conf. on Low Temperature Physics A (1965) 396.

[8] H. A. Schwettman, et al., IEEE Trans. Nucl. Sci NS-14 (1967) 336.

[9] A. Citron, Proc. 1970 Proton Linear Accelerator Conference, Batavia (1970) 239.

[10] A. Brandelik, A. Citron, et al., Proc. Proton Linear Acc. Conf., Oct. 10-13,1972, Los Alamos (1972)

93.

[11] K. Miltag, IEEE Trans. Nucl. SciNS-24 (1977) 1156.

[12] M. Kuntze, Proc .1976 Proton Linear Acc. Conf., Sept. 14-17, 1976, Chalk River (1976) 86.

[13] D. Schulze, et al., Proc. Proton Linear Acc. Conf., Oct. 10-13,1972, Los Alamos (1972) 156.

[14] R. Benaroya, et al., Proc. Proton Linear Acc. Conf., Oct. 10-13,1972, Los Alamos (1972) 168.

[15] G. J. Dick and K. W. Shepard, Proc. 1972 Applied Supercondcuctivity Conf., Annapolis (1972) 649.

[16] J. E. Vetter, B. Piosczyk, et al., Proc. Proton Linear Acc. Conf., Oct. 10-13,1972, Los Alamos (1972) 145.

[17] P. H. Cepperly, I. Ben-Zvi et al., IEEE Trans. Nucl. Sci. NS-22 (1975) 1153.

[18] E. Jaeschke, et al., Proc .1976 Proton Linear Acc. Conf., Sept. 14-17, 1976, Chalk River (1976) 112.

[19] B. Cauvin, et al., Proc. 3rd Workshop on RF Superconductivity, Argonne (1988) 379.

[20] G. J. Dick and K. W. Shepard, Appl. Phys. Lett. 24 (1974) 40. 
[21] K. W. Shepard, J. E. Mercereau, and G. J. Dick, IEEE Trans. Nucl. Sci. NS-22 (1975) 1179.

[22] J. Noe, et al, IEEE Trans. Nucl. Sci. NS-24 (1977) 1144.

[23] J. M. Brennan, et al., IEEEE Trans. Nucl. Sci. NS-32 (1985) 3122.

[24] R. Benaroya, et al., IEEE Trans. Magn. MAG-11 (1974) 413.

[25] K. W. Shepard, et al., IEEE Trans. Nucl. Sci. NS-24 (1977)1147.

[26[ J. Aron, et al, Proc. 1979 Linear Accelerator Conf. , Montauk, N. Y.(1979) 511.

[27] J. S. Sokolowski, et al, IEEE Trans. Nucl. Sci. NS-24 (1977) 1141.

[28] K. W. Shepard, IEEE Trans. Nucl. Sci. NS-28 (1981) 3248.

[29] K. W. Shepard, et al., IEEE Trans. Nucl. Sci. NS-30 (1983) 3339.

[30] K. W. Shepard, Proc. 1986 Linear Acc. Conf., Stanford (1986) 269.

[31] J. Noe, et al., IEEE Trans. Nucl. Sci. NS-24 (1977) 1144.

[32] J. Delayen, et al., IEEE Trans. Magn. MAG-17 (1981) 939

[33] I. Ben-Zvi and J. M. Brennan, Nucl. Instrum. Methods 212 91983) 73.

[34] D. W. Storm, et al., Proc. 3rd Workshop on RF Superconductivity, Argonne (1988) 173.

[35] S. Takeuchi, Proc. 3rd Workshop on RF Superconductivity, Argomne (1988) 429.

[30] A. M. Porcellato, et al., Proc. 6th Workshop on RF Superconductivity, CEBAF (1994) 110.

[37] K. W. Shepard, A. Roy, et al., Proc. 1993 IEEE Part. Acc. Conf. , Washington (1993) 1045.

[38] E. G. Meyers, et al., Proc. 3rd Workshop on RF Superconductivity, Argonne (1988) 405.

[39] T. Gray, Rev. Sci. Instrum. 57 (1986) 783.

[40] J. C. Acquadro, N. Added, et al, Proc. 1992 Linear Acc. Conf. (Ottawa) 1992) 175.

[41] D. Weisser, et al., in the Proceedings of this conference.

[42] L. M. Bollinger, et al., Proc. 1986 Linear Acc. Conf., Stanford (1986) 260.

[43] S. Takeuchi, in the Proceedings of this conference.

[44] A. Roy, et al., to be published in the Proceedings of the 1995 Linear Accelerator Conference.

[45] A. Dainelli, et al, in the Proceedings of this conference.

[46] A. M. Porcellato, et al. , in the Proceedings of this conference.

[47] V. Palmieri, et al., IFEE Trans. Appl. Superconductivity 3 (1993) 193. 
[48] J. R. Delayen, et al, Proc. 5th Workshop on RF Superconductivity, Hamburg (1991) 376.

[49] J. R. Delayen and K. W. Shepard, Appl. Phys. Lett. 57 (1990) 514.

[50] I. Ben-Zvi, et al., Proc. 6th Workshop on RF Superconductivity, CEBAF (1994) 160.

[51] K. W. Shepard, et al., Proc. 1993 IEEE Part. Acc. Conf. , Washington (1993) 1042.

\section{Figure and Table Captions}

Fig. 1. Heavy-ion accelerating structures being developed in 1977.

Fig. 2. A $150 \mathrm{MHHz}$ split-ring for the booster linac at SUNY Stony Brook, before electroplating with lead and final assembly.

Fig. 3. Elements of a niobium $97 \mathrm{MHz}$ coaxial quarter-wave line structure being developed for a booster linac at the Center for Nuclear Research in New Delhi.

Table I. Parameters and operating characteristics for the superconducting structures used in heavy-ion booster linacs. The entries for peak surface fields and if energy stored are referenced to an accelerating field of $1 \mathrm{MV} / \mathrm{m}$. For further details, see the text.

\section{DISCLAIMER}

This report was prepared as an account of work sponsored by an agency of the United States Government. Neither the United States Government nor any agency thereof, nor any of their employees, makes any warranty, express or implied, or assumes any legal liability or responsibility for the accuracy, completeness, or usefulness of any information, apparatus, product, or process disclosed, or represents that its use would not infringe privately owned rights. Reference herein to any specific commercial product, process, or service by trade name, trademark, manufacturer, or otherwise does not necessarily constitute or imply its endorsement, recommendation, or favoring by the United States Government or any agency thereof. The views and opinions of authors expressed herein do not necessarily state or reflect those of the The submitted manuscriot has been authored by a contrator of the U.S. Government under controct No. W-31-109ENG-38. Accordingly, the U.S. Government retains a nonexclutive, royalty-free license to publish or reproducs the published form of this contribution, or lllow others to do 20 , for U.S. Government purpows.

United States Government or any agency thereof. 
TABLE I

\begin{tabular}{|c|c|c|c|c|c|c|c|c|c|c|c|}
\hline Institution & Date & Cavlty Type & $\begin{array}{l}\text { Frequency } \\
\mathrm{MHz}\end{array}$ & $\begin{array}{l}\text { Optlmum } \\
\text { Veloclty }\end{array}$ & $\begin{array}{l}\text { No. On- } \\
\text { llne }\end{array}$ & $\begin{array}{l}\text { Length } \\
\mathrm{cm} \text {. }\end{array}$ & $\begin{array}{l}\text { Ave. Ea } \\
\mathrm{MV} / \mathrm{m}\end{array}$ & $\frac{\text { Peak } f}{\text { Ep }}$ & $\frac{d s}{B p}$ & $\begin{array}{l}\text { KF Energy } \\
\text { millijoules }\end{array}$ & Ref. \\
\hline Argonne Nall. Laboratory & $\begin{array}{r}1978 \\
1981 \\
* 1982 \\
* 1983 \\
1988 \\
1988 \\
1988 \\
1988\end{array}$ & 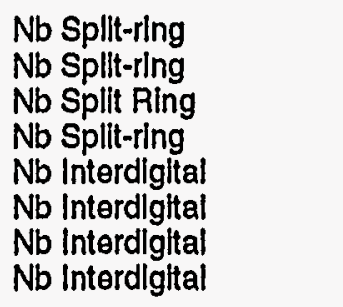 & $\begin{array}{r}97.00 \\
97.00 \\
145.50 \\
145.50 \\
48.50 \\
48.50 \\
48.50 \\
72.75\end{array}$ & $\begin{array}{l}0.105 \\
0.065 \\
0.16 \\
0.155 \\
0.008 \\
0.015 \\
0.023 \\
0.035\end{array}$ & $\begin{array}{r}34 \\
12 \\
2 \\
8 \\
1 \\
2 \\
5 \\
10\end{array}$ & $\begin{array}{l}35.6 \\
20.3 \\
35.6 \\
35.6 \\
10.2 \\
16.5 \\
25.4 \\
25.4\end{array}$ & $\begin{array}{l}2.9 \\
3.2 \\
2.5 \\
2.5 \\
4.3 \\
3.3 \\
3.5 \\
3.7\end{array}$ & $\begin{array}{l}4.8 \\
4.7 \\
3.9 \\
4.8 \\
4.5 \\
4.1 \\
4.4 \\
4.4\end{array}$ & $\begin{array}{r}182 \\
129 \\
145 \\
260 \\
104 \\
75 \\
82 \\
103\end{array}$ & $\begin{array}{r}161 \\
70 \\
149 \\
129 \\
38 \\
104 \\
182 \\
141\end{array}$ & $\begin{array}{l}{[25]} \\
{[28]} \\
{[29]} \\
{[29]} \\
{[30]} \\
{[30]} \\
{[30]} \\
{[30]}\end{array}$ \\
\hline SUNY Stony Brook & $\begin{array}{l}1983 \\
1983 \\
1990\end{array}$ & $\begin{array}{l}\mathrm{Pb} / \mathrm{Cu} \text { Split-ring (CIT) } \\
\text { pb/Cu Splltr-ring (ClT) } \\
\text { Pb/Cu Quarter-wave }\end{array}$ & $\begin{array}{l}150.40 \\
150.40 \\
150.40\end{array}$ & $\begin{array}{l}0.055 \\
0.105 \\
0.068\end{array}$ & $\begin{array}{l}1 \\
25 \\
16\end{array}$ & $\begin{array}{l}14.0 \\
22.0 \\
17.0\end{array}$ & $\begin{array}{r}1.5-2.0 \\
2.0-3.0 \\
3.0\end{array}$ & $\begin{array}{l}5.5 \\
4.3 \\
6.5\end{array}$ & $\begin{array}{l}105 \\
105 \\
75\end{array}$ & $\begin{array}{l}17 \\
47 \\
39\end{array}$ & $\begin{array}{l}{[31]} \\
{[32]} \\
{[33]}\end{array}$ \\
\hline Florlda State Unlversity & $\begin{array}{l}1987 \\
1987\end{array}$ & $\begin{array}{l}\text { Nb Spllt-ring (ANL) } \\
\text { Nb Split-ring (ANL) }\end{array}$ & $\begin{array}{l}97.00 \\
97.00\end{array}$ & $\begin{array}{l}0.065 \\
0.105\end{array}$ & $\begin{array}{r}1 \\
13\end{array}$ & $\begin{array}{l}20.3 \\
35.6\end{array}$ & $\begin{array}{r}2.0-3.0 \\
2.5\end{array}$ & $\begin{array}{l}4.7 \\
4.8\end{array}$ & $\begin{array}{l}129 \\
182\end{array}$ & $\begin{array}{r}70 \\
161\end{array}$ & $\begin{array}{l}\text { [28] } \\
\text { [25] }\end{array}$ \\
\hline University of Washington & $\begin{array}{l}1988 \\
1988\end{array}$ & $\begin{array}{l}\mathrm{Pb} / \mathrm{Cu} \text { Quarter-wave } \\
\mathrm{Pb} / \mathrm{Cu} \text { Quarter-wave }\end{array}$ & $\begin{array}{l}148.90 \\
148.90\end{array}$ & $\begin{array}{l}0.100 \\
0.200\end{array}$ & $\begin{array}{l}25 \\
12\end{array}$ & $\begin{array}{l}18.0 \\
35.4\end{array}$ & $\begin{array}{l}3.0 \\
3.0\end{array}$ & $\begin{array}{l}5.0 \\
4.5\end{array}$ & $\begin{array}{l}70 \\
77\end{array}$ & $\begin{array}{r}63 \\
252\end{array}$ & [34] \\
\hline CEN Saclay & $\begin{array}{l}* 1988 \\
* 1988\end{array}$ & $\begin{array}{l}\mathrm{Nb} \text { Half-wave Hellx } \\
\mathrm{Nb} \text { Full-wave Hellx }\end{array}$ & $\begin{array}{r}81.00 \\
135.00\end{array}$ & $\begin{array}{l}0.085 \\
0.085\end{array}$ & $\begin{array}{l}16 \\
34\end{array}$ & $\begin{array}{l}26.0 \\
26.0\end{array}$ & $\begin{array}{l}2.2 \\
2.3\end{array}$ & $\begin{array}{l}7.4 \\
8.4\end{array}$ & $\begin{array}{l}372 \\
267\end{array}$ & $\begin{array}{l}790 \\
560\end{array}$ & {$[19]$} \\
\hline Kansas State Unlversity & $\begin{array}{l}1990 \\
1990\end{array}$ & $\begin{array}{l}\mathrm{Nb} \text { Split-ring (ANL) } \\
\mathrm{Nb} \text { Split-ring (ANL) }\end{array}$ & $\begin{array}{l}97.00 \\
97.00\end{array}$ & $\begin{array}{l}0.065 \\
0.105\end{array}$ & $\begin{array}{l}9 \\
5\end{array}$ & $\begin{array}{l}20.3 \\
35.6\end{array}$ & $\begin{array}{l}2.0-3.0 \\
2.0-3.0\end{array}$ & $\begin{array}{l}4.7 \\
4.8\end{array}$ & $\begin{array}{l}129 \\
182\end{array}$ & $\begin{array}{r}70 \\
161\end{array}$ & $\begin{array}{l}\text { [28] } \\
{[25]}\end{array}$ \\
\hline JAERI & 1994 & Pb/Cu Quarter-wave & 129.80 & 0.100 & 44 & 15.0 & 5.0 & 4.6 & 75 & 46 & [35] \\
\hline INFN Legnaro & $\begin{array}{l}1994 \\
1995 \\
1995\end{array}$ & $\begin{array}{l}\mathrm{Pb} / \text { Cu Quarter-wave } \\
\mathrm{Nb} \text { Quarter-wave } \\
\mathrm{Pb} / \mathrm{Cu} \text { Quarter-wave }\end{array}$ & $\begin{array}{r}160.00 \\
80.00 \\
160.00\end{array}$ & $\begin{array}{l}0.110 \\
0.055 \\
0.14\end{array}$ & $\begin{array}{r}48 \\
1 \\
4\end{array}$ & $\begin{array}{l}18.0 \\
18.0\end{array}$ & $\begin{array}{l}2.3 \\
4.0 \\
3.5\end{array}$ & $\begin{array}{l}4.6 \\
4.9 \\
4.6\end{array}$ & $\begin{array}{l}104 \\
100 \\
104\end{array}$ & $\begin{array}{r}64 \\
114 \\
64\end{array}$ & $\begin{array}{l}{[36]} \\
{[36]} \\
{[36]}\end{array}$ \\
\hline Oxford/Daresbury/Canberra & 1995 & Pb/Cu Spllt-ring (CIT) & 150.40 & 0.105 & 10 & 22.0 & $2.0-3.0$ & 4.3 & 105 & 47 & [32] \\
\hline University of Sao Paulo & $\begin{array}{l}\text { constr. } \\
\text { constr. }\end{array}$ & $\begin{array}{l}\mathrm{Nb} \text { Split-ring (ANL) } \\
\mathrm{Nb} \text { Split-ring (ANL) }\end{array}$ & $\begin{array}{l}97.00 \\
97.00\end{array}$ & $\begin{array}{l}0.065 \\
0.105\end{array}$ & $\begin{array}{r}4 \\
10\end{array}$ & $\begin{array}{l}20.3 \\
35.6\end{array}$ & $\cdots$ & $\begin{array}{l}4.7 \\
4.8\end{array}$ & $\begin{array}{l}129 \\
182\end{array}$ & $\begin{array}{r}70 \\
161\end{array}$ & 28] \\
\hline CNR New Delhi & constr. & $\mathrm{Nb}$ Quarter-wave & 97.00 & 0.081 & 32 & 20.0 & -.... & 3.9 & 108 & 116 & 7] \\
\hline
\end{tabular}



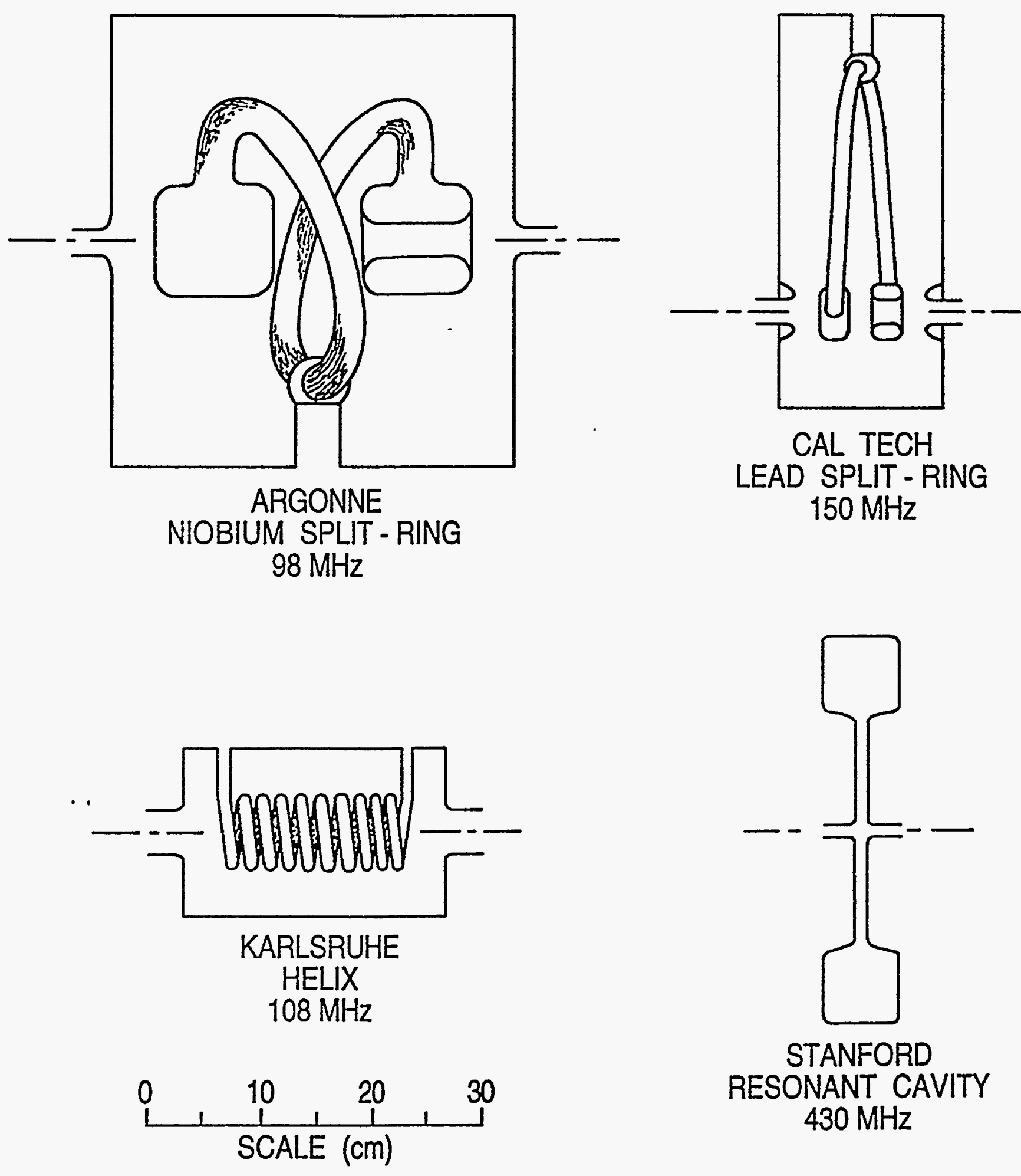

STANFORD

RESONANT CAVITY $430 \mathrm{MHz}$

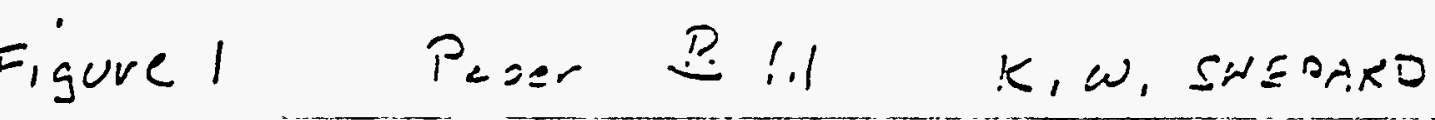




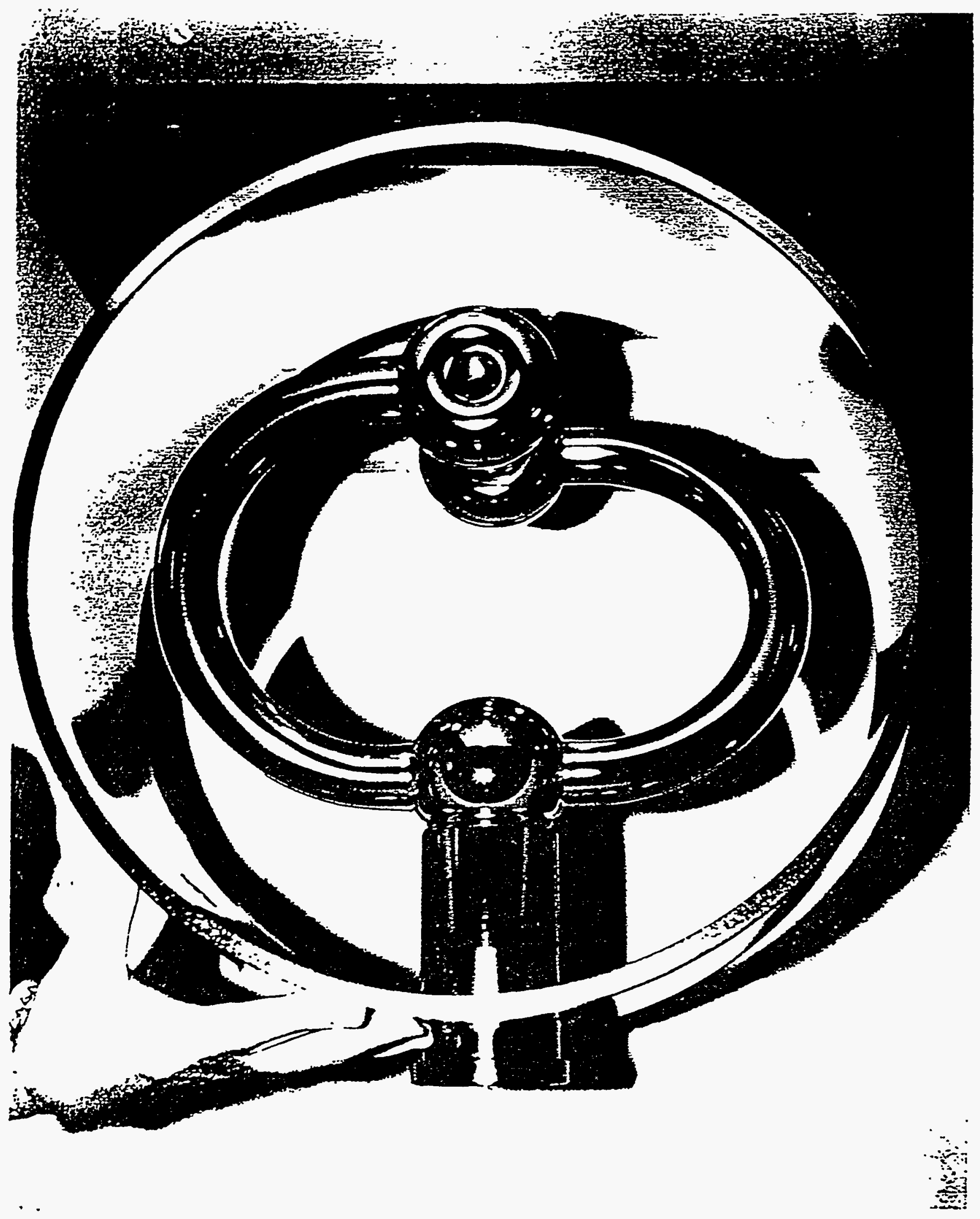

Fig. 2 paper B 1.1 K. W. Shepard 


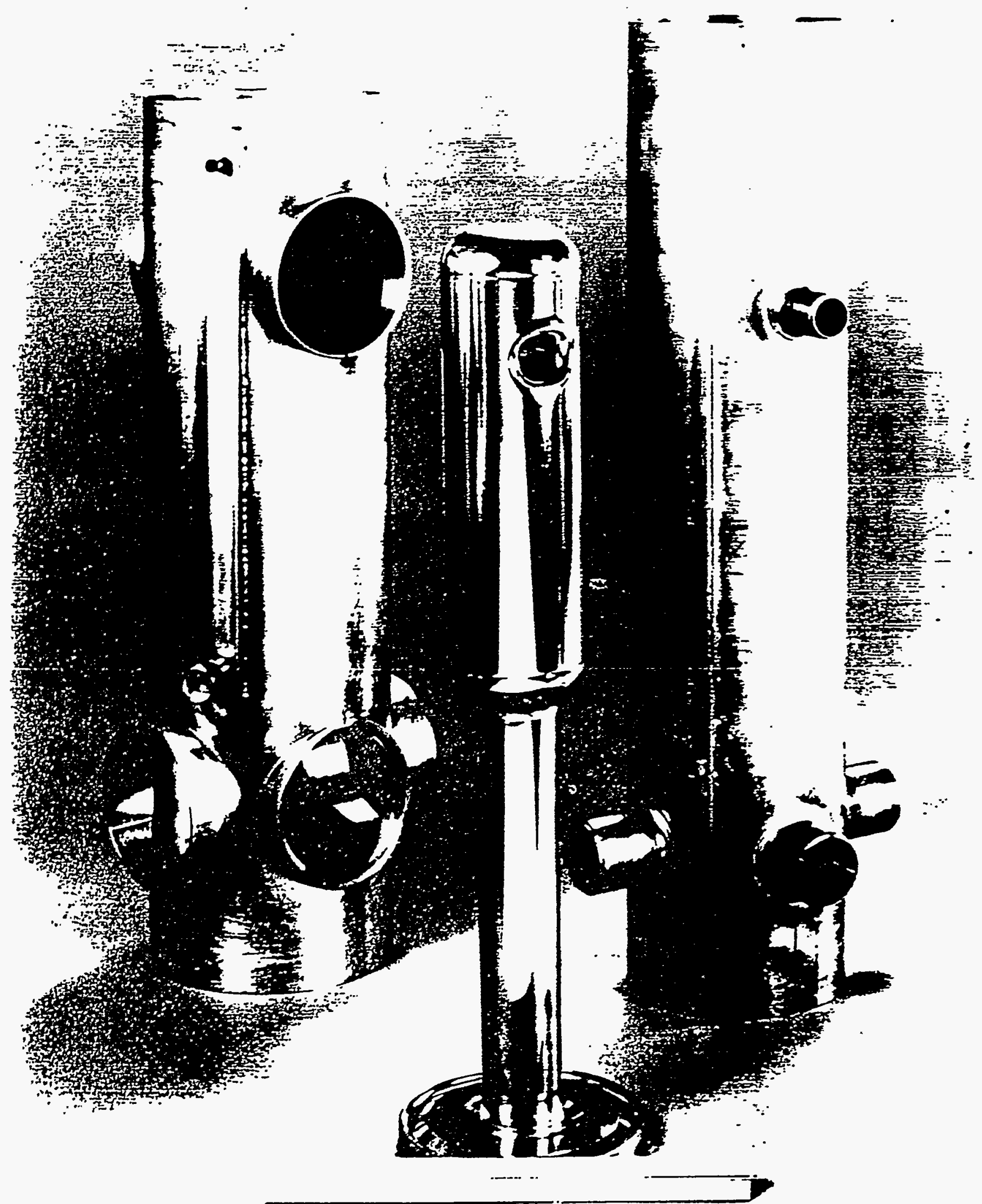

Fig. 3

Daper $\mathrm{B} 1.1$

K. W. Shepard 